European Association for the Development of Renewable Energies, Environment and Power Quality
International Conference on Renewable Energies and Power Quality (ICREPQ’09)

Valencia (Spain), 15th to 17 th April, 2009

\title{
Dynamic Response Analysis of Small Wind Energy Conversion Systems (WECS) Operating With Torque Control versus Speed Control
}

\author{
L. G. González ${ }^{1}$, E. Figueres ${ }^{2}$, G. Garcerá2 ${ }^{2}$ O. Carranza ${ }^{3}$ \\ ${ }^{1}$ Departamento de Electrónica y Comunicaciones, Universidad de los Andes, Mérida, Venezuela. \\ Phone:+0058 02742402907, e-mail: lgerardo@ula.ve, \\ ${ }^{2}$ Departamento de Ingeniería Electrónica - UPV, Camino de Vera S/N, 7F, Valencia, 46022, España. \\ Phone:+0034 963876001, e-mail: efiguere@eln.upv.es, ggarcera@eln.upv.es
}

${ }^{3}$ Escuela Superior de Cómputo - Instituto Politécnico Nacional, Av. Juan de Dios Bátiz S/N, D. F., 07738 , México. Phone:+005255576000,Ext: 52020 ,e-mail: ocarranzac@ipn.mx

\begin{abstract}
This paper encompasses the study of modelling and design of WECS, using a wind turbine with known dynamic characteristics and a permanent magnet synchronous generator with a back to back power converter topology. The dynamic modeling allows to know the response of the turbine generator system in the whole range of operation.
\end{abstract}

\section{Keywords}

Torque control, Speed control, Wind Energy Conversion Systems, Maximum Power Point Tracker.

\section{1.- INTRODUCTION}

The necessity of clean and renewable energy has increased the studies in new technologies, such as the wind energy and its multiple applications. The main objective of researches in the energy generator systems are aimed at an increase in the performance, extension of equipment useful life and average time reduction between failures. For that reason it is necessary to have a good knowledge of the dynamic response of the turbine system, generator and the power converter. This paper studies the dynamic operation of a control system for wind energy generators, composed by a fast wind turbine with known dynamic characteristics, a permanent magnet synchronous generator (PMSG), and a back to back power converter topology with vector control $I_{d}=0$. Figure 1 shows the conversion system structure, which operates in both the Maximum Power Point Tracker (MPPT) region and the nominal power region for high speed wind. Also, the proposed system power management uses a position and speed estimation technique, in this case is the simplified Extended Kalman Filter (EKF) [1].

\section{2.- Model of Permanent Magnet SYNCHRONOUS GENERATORS (PMSG) AND Wind TURBINE}

\section{A.- Model PMSG.}

The equivalent model of PMSG [2], view figure 2, with a sinusoidal flux distribution is shown by equation (1). Where $R_{s}$ and $L_{s}$ are the machine internal resistive and inductance respectively, $u_{a}$ is the phase to neutral terminal voltage and $e_{a}$ is the phase to neutral electromotive force (EMF) driven by the permanent magnets. Equation (2) and (3) are the result of modeling the PSMG in a synchronous reference frame $d q$.

$$
\begin{gathered}
\frac{d}{d t}\left[\begin{array}{l}
i_{a} \\
i_{b} \\
i_{c}
\end{array}\right]=-\frac{R_{s}}{L}\left[\begin{array}{l}
i_{a} \\
i_{b} \\
i_{c}
\end{array}\right]+\frac{1}{L}\left[\begin{array}{l}
e_{a} \\
e_{b} \\
e_{c}
\end{array}\right]-\frac{1}{L}\left[\begin{array}{l}
u_{s a} \\
u_{s b} \\
u_{s c}
\end{array}\right]+\frac{V_{n}}{L} \\
u_{s d}=-R_{s} i_{s d}+\omega_{e} \psi_{s q}-\dot{\psi}_{s d} \\
u_{s q}=-R_{s} i_{s q}-\omega_{e} \psi_{s d}-\dot{\psi}_{s q}
\end{gathered}
$$

Where the induced flux in the machine stator is described by (4) and (5):

$$
\begin{aligned}
& \psi_{s d}=L_{d} i_{s d}-\Psi_{P M} \\
& \psi_{s q}=L_{q} i_{s q}
\end{aligned}
$$




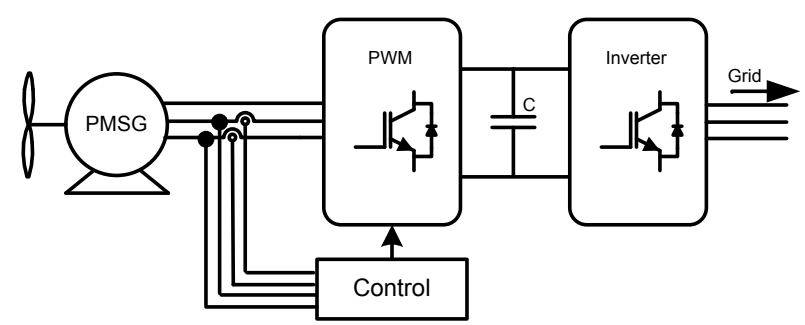

Fig. 1, Framework WECS

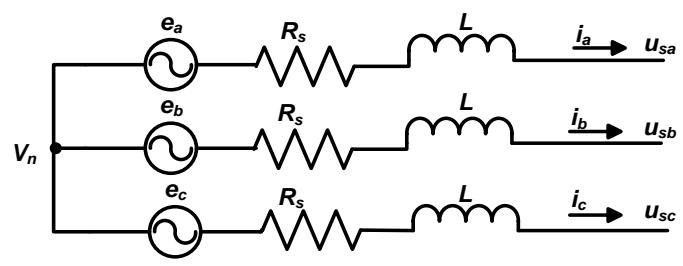

Fig.2 Equivalent Circuit for PMSG.

$u_{s d}$ and $u_{s q}$ are the stator terminal voltages, $i_{s d}$ and $i_{s q}$ are the stator currents, $\Psi_{P M}$ is the magnetic flux produced by the permanents magnets, and $L_{d}$ and $L_{q}$ are the stator inductances in the synchronous reference system $d q$. The electrical torque applied to the PMSG rotor is represented by (6). If the PMSG is taken as without rotor saliency (where $L_{d}=L_{q}=L$ ), the electrical torque can be simplified as (7).

$$
\begin{gathered}
T_{e}=\frac{P}{2}\left[\left(L_{d}-L_{q}\right) i_{s d} i_{s q}-\Psi_{P M} i_{s q}\right] \\
T_{e}=\frac{P}{2}\left[\Psi_{P M} i_{s q}\right]
\end{gathered}
$$

Where $P$ is the number of the machine poles.

The system parameters are described in table 1.

\begin{tabular}{|l|c|}
\hline \multicolumn{2}{|c|}{ Table 1} \\
\hline Number of poles $P$ & 12 \\
\hline Armature resistance & $5 \Omega$ \\
\hline Armature Inductances $L_{d}=L_{q}=L$ & $25 \mathrm{mh}$. \\
\hline $\begin{array}{l}\text { Amplitude of the flux linkages } \\
\text { coefficient }\end{array}$ & $\begin{array}{c}0.9022 \\
\text { volt } / \mathrm{rad} / \mathrm{s}\end{array}$ \\
\hline DC link Voltage & $800 \mathrm{volt}$. \\
\hline Switching frecuency & $5 \mathrm{Khz}$. \\
\hline Sampling time & $10 \mu \mathrm{s}$. \\
\hline Inertia coefficient systems & $0.0833 \mathrm{~kg} *$ \\
$\mathrm{~m}^{2} \mathrm{~s}^{2}$ \\
\hline$C_{p}=0.043-0.108 \lambda+0.146 \lambda^{2}-0.0605 \lambda^{3}+0.0104 \lambda^{4}-$ \\
\hline \multicolumn{2}{|c|}{$0.0006 \lambda^{5}$} \\
\hline $\begin{array}{l}V_{\text {wind }}(t)=10+2 \cdot \sin (\omega t)+2 \cdot \sin (3.5 \cdot \omega t)+ \\
\text { sin }(12.5 \cdot \omega t)+0.2 \cdot \sin (35 \cdot \omega t), \omega=2 \pi / 60 \mathrm{rad} / \mathrm{s} .\end{array}$ \\
\hline
\end{tabular}

\section{B.- Wind Turbine Model.}

The power generated by the turbine is modeled by equation (8), where $\rho$ is the density of the air, $R$ is the wind turbine ratio, $V$ is the wind speed, and $C_{p}(\lambda)$ is the loss power coefficient, which depends of the tip-speedratio parameter, $(\lambda)$, showed in equation (9), where $\omega$ is the turbine rotational speed expressed in $\mathrm{rad} / \mathrm{s}$.

$$
\begin{gathered}
P_{r}=\frac{1}{2} \rho \pi R^{2} C_{p}(\lambda) V^{3} \\
\lambda=\frac{R \omega}{V}
\end{gathered}
$$

From equation (8), the dynamic model for the wind turbine torque is described by equation (10)

$$
T_{r}=\frac{1}{2} \rho \pi R^{3} C_{q}(\lambda) V^{2}
$$

Where $C_{q}(\lambda)$, is the torque loss coefficient represented by equation (11).

$$
C_{q}(\lambda)=\frac{C_{p}(\lambda)}{\lambda}
$$

\section{3.- SPEed Control Model}

The mechanical system is composed by a wind turbine and a PMSG, which dynamics follow equation (12). Where $J$ is the turbine and rotor system inertia in $\mathrm{Kg} \cdot \mathrm{m} / \mathrm{s}^{2}, \quad B_{r}$ is the friction coefficient that will be insignificant for later analysis, $T_{r}$ is the wind turbine torque, and $T_{e}$ is the PMSG electromagnetic torque. By linearizing $\widehat{T}_{r}$ and $\widehat{T}_{e}$, using a first order Taylor series in equations (13) and (14), the system model analysis is similar to the one used in [3]. Equation (15) shows the active current generator to PMSG speed transfer function. Figure 3 shows the bode diagram of the speed control loop, for different values of Lambda $(\lambda)$ and also in the ideal case where $\left(T_{r}=0\right)$. Note the sensitivity of the speed control loop to variations of $\lambda$. As a result, the stability of that control system could be compromised if an excessively low crossover frequency were chosen.

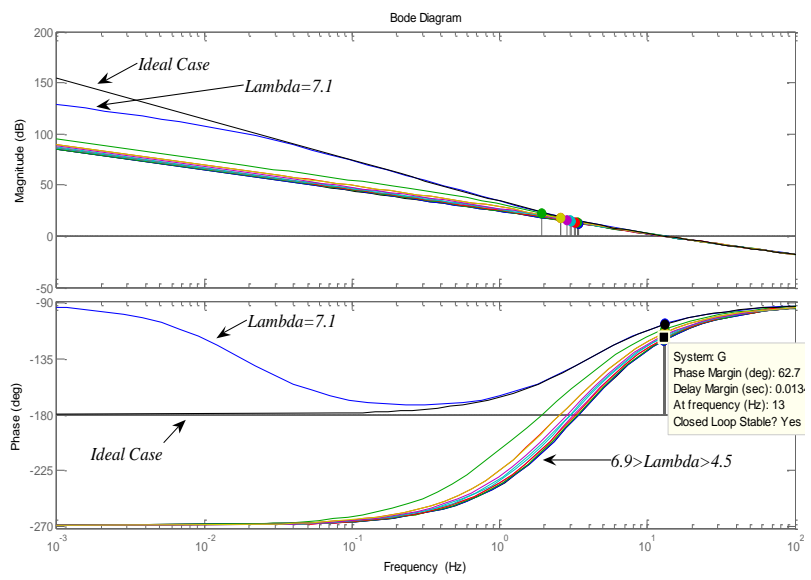

Fig. 3, Dynamic Response Speed Control Loop 


$$
\begin{gathered}
J \frac{d \omega}{d t}=T_{r}-T_{e}-B_{r} \omega \\
\hat{T}_{r}=\left.\frac{\partial\left[T_{r}(\omega, V)\right]}{\partial \omega}\right|_{\substack{\omega=\bar{\omega} \\
V=\bar{V}}} \cdot \widehat{\omega}+\left.\frac{\partial\left[T_{r}(\omega, V)\right]}{\partial V}\right|_{\substack{\omega=\bar{\omega} \\
V=\bar{V}}} \cdot \hat{V} \\
\widehat{T}_{e}=\left.\frac{\partial\left[T_{e}\left(i_{s q}\right)\right]}{\partial i_{s q}}\right|_{i_{s q}=\bar{l}_{s q}} \cdot \hat{\imath}_{s q}=-\frac{P}{2} \Psi_{P M} \hat{\imath}_{s q} \\
\frac{\widehat{\omega}(s)}{\hat{\imath}_{s q}(s)}=\frac{-\frac{P}{2 J} \Psi_{P M}}{s-\left.\frac{1}{J} \cdot \frac{\partial\left[T_{r}(\omega, V)\right]}{\partial \omega}\right|_{\begin{array}{c}
\omega=\bar{\omega} \\
V=\bar{V}
\end{array}}}
\end{gathered}
$$

\section{4.- DESCRIPTION OF THE CONTROL STRUCTURE}

\section{A.- Regions of Operation.}

The proposed power management in the WECS structure changes depending on the operation region. The wind turbine and electric generator group, generally operate in four main operation regions [5] as figure 4 shows. The operation regions are:

1) Region 1: in this region the wind speed is inferior to the connection speed, or the power generated by the turbine doesn't exceed the system losses.

2) Región 2: (MPPT region) In this region a MPPT algorithm (in this case, the perturb and observe algorithm) allows to calculate the proper rotor speed control to extract the highest wind power, Figure 4 shows area between 5 and $14 \mathrm{~m} / \mathrm{s}$, approximately. The aerodynamic losses avoid that the turbine obtains the maximum theory wind power, these losses are called Betz Limit, but the goal is being as close as possible to the Betz Limit.

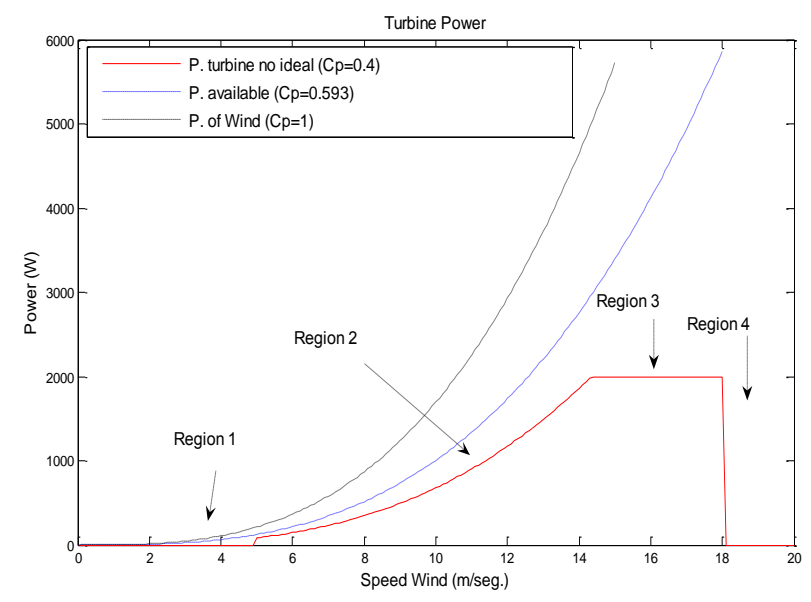

Fig.4, Regions of Operation Wind Turbine
3) Región 3: The system works in this region when the nominal power (Constant Power CP region) is reached, in this region the turbine should limit the available wind power, to not exceed the maximum designed power.

4) Región 4: Figure 4 shows that for a wind speed of $18 \mathrm{~m} / \mathrm{s}$, the power generated by the system cannot be controlled, for this reason is mandatory to stop the turbine rotation.

Figure 5, shows the performance in both MPPT region and $\mathrm{CP}$ region for several wind speeds.

\section{B.- Power Management with Torque Control versus Speed Control.}

A torque control scheme can be used to regulate the WECS power by controlling the generator active current, which has a linear relationship with the PMSG electromagnetic torque. With this approach the output power is determined by equation (16), after neglecting losses among the air gap and the converter. The active current to power transfer function can be obtained by linearizing equation (16) around an operation point and combining equations (15) and (17).This transfer function, following (18) shows a pole and a zero in the right semiplane for different operation points. Because of the poles and zeros locations, the regulator is chosen following [4].

Figure 6 shows the open-loop dynamics of the current to power transfer function for different operation points. Note that with such dynamic response it's very difficult to design a stable closed loop power control.

The speed to power transfer function, can be obtained as expressed by (19), starting from equations (15) and (18), and neglecting the small-signal variations of the wind speed. This is a first order transfer function with a zero in the right semiplane.

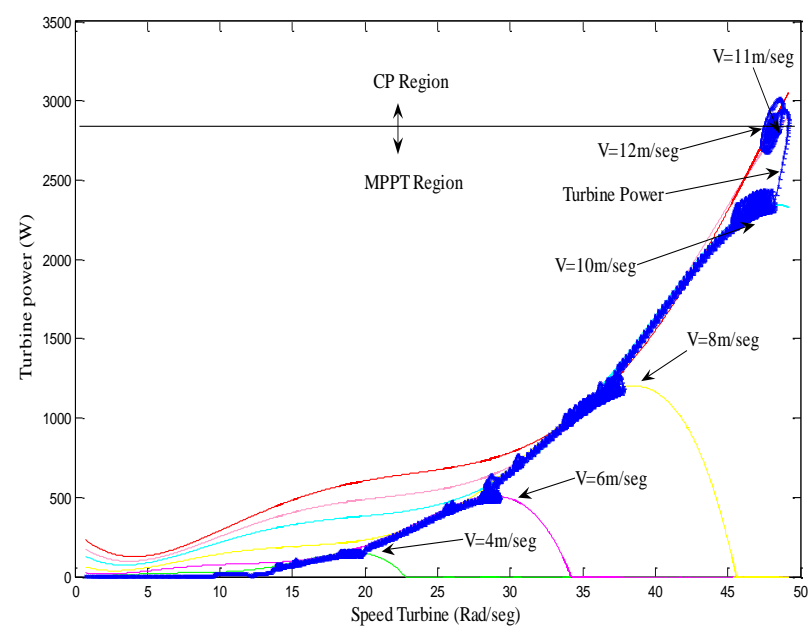

Fig. 5, Regulated power for several wind speed. 


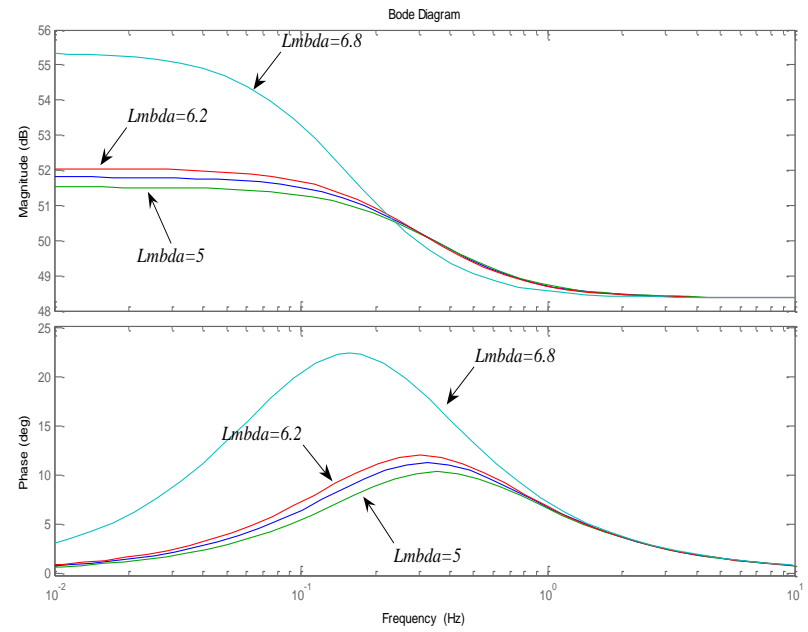

Fig.6, Dynamic response open loop power vs. current

The regulator used to obtain a stable dynamic response is shown by equation (20), with $K_{i}=0.08$. Figure 7 shows the described control structure, which works in the MPPT region for low wind speeds working in the $\mathrm{CP}$ region for high wind speeds with selection of both power and speed control.

$$
\begin{aligned}
& P_{\text {out }}=\frac{P}{2} \Psi_{P M} i_{s q} \omega-R_{s} i_{s q}^{2} \\
& \hat{P}_{\text {out }}(s)=\frac{P}{2} \Psi_{P M} \bar{l}_{s q} \cdot \widehat{\omega}(s)+ \\
& \left(\frac{P}{2} \Psi_{P M} \bar{\omega}-2 R_{s} \bar{l}_{s q}\right) \cdot \hat{\imath}_{s q}(s) \\
& \frac{\hat{P}_{o u t}(s)}{\hat{\imath}_{s q}(s)}=\left(\frac{P}{2} \Psi_{P M} \bar{\omega}-2 R_{s} \bar{l}_{s q}\right) . \\
& s-\left(\left.\frac{1}{J} \cdot \frac{\partial\left[T_{r}(\omega, V)\right]}{\partial \omega}\right|_{\substack{\omega=\bar{\omega} \\
V=\bar{V}}}+\frac{\frac{\bar{l}_{s q}}{J}\left(\frac{P}{2} \Psi_{P M}\right)^{2}}{\frac{P}{2} \Psi_{P M} \bar{\omega}-2 R_{s} \bar{l}_{s q}}\right) \\
& s-\left.\frac{1}{J} \cdot \frac{\partial\left[T_{r}(\omega, V)\right]}{\partial \omega}\right|_{\substack{\omega=\bar{\omega} \\
V=\bar{V}}} \\
& \frac{\hat{P}_{\text {out }}(s)}{\widehat{\omega}(s)}=-\frac{\left(\frac{P}{2} \Psi_{P M} \bar{\omega}-2 R_{s} \bar{\imath}_{s q}\right)}{\frac{P}{2 J} \Psi_{P M}} . \\
& {\left[s-\left(\left.\frac{1}{J} \cdot \frac{\partial\left[T_{r}(\omega, V)\right]}{\partial \omega}\right|_{\substack{\omega=\bar{\omega} \\
V=\bar{V}}}+\frac{\frac{\bar{l}_{s q}}{J}\left(\frac{P}{2} \Psi_{P M}\right)^{2}}{\frac{P}{2} \Psi_{P M} \bar{\omega}-2 R_{s} \bar{l}_{s q}}\right)\right]}
\end{aligned}
$$

$$
G_{p}(s)=\frac{K_{i}}{s}
$$

The rotor speed to power transfer function speed presents a stable closed-loop dynamic, as figure 8 shows, for a crossover frequency of $1 \mathrm{~Hz}$.

\section{5.- Simulation Results}

Figure 10 shows the control performance in the MPPT and $\mathrm{CP}$ region, for a wind speed evolution as show in figure 9. The MPPT region can take advantage of the maximum power available at low speed wind with a linear speed control loop, and a perturb and observe algorithm. The control structure changes to the $\mathrm{CP}$ region when the nominal power is reached using an external loop power control and an internal speed control loop. The rotor speed keeps stable in both regions for different speed winds.

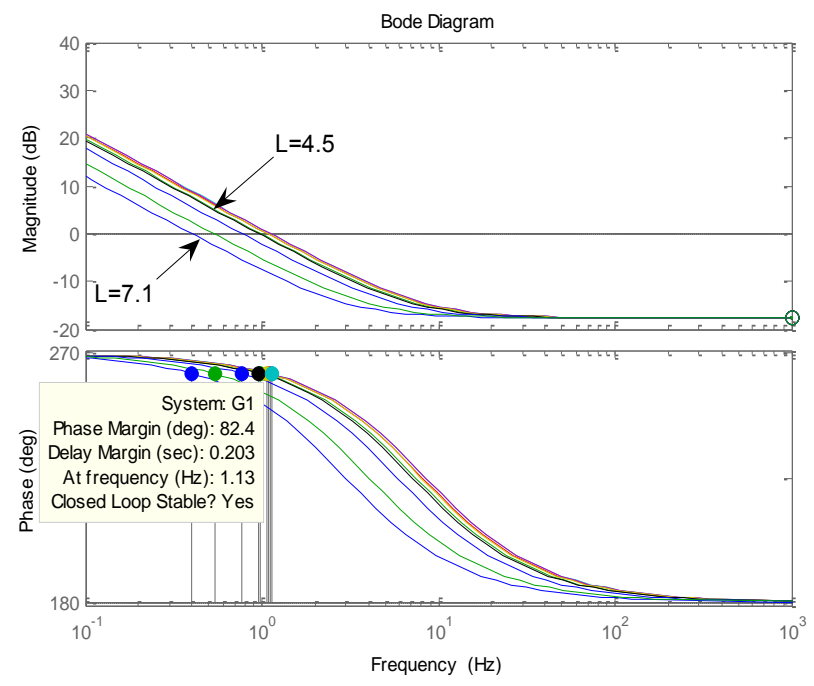

Fig. 8, Bode Plot of the rotor speed to power transfer function.

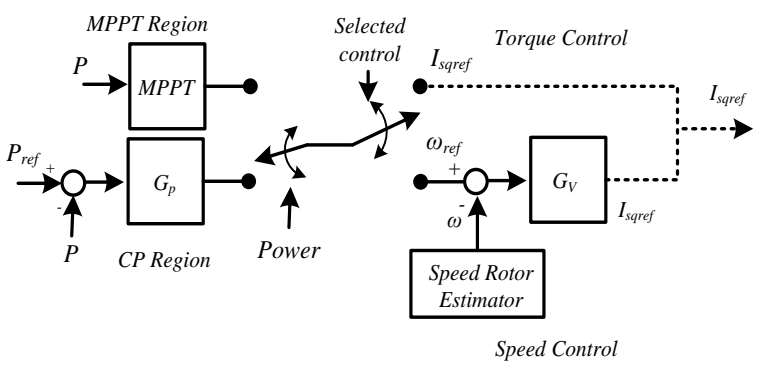

Fig. 7, Power management with torque or speed control 
4] Boubekeur B. and Houria S." Nonlinear Control of Variable Speed Wind Turbines for Power Regulation"Proceedings of the 2005 IEEE Conference on Control Applications Toronto, Canada, August 28-31, 2005.

[5] B. Neammanee, S. Sirisumranukul, S. Chatratana "Control Performance Analysis of Feedforward and Maximum Peak Power Tracking for Small- and Medium-Sized Fixed Pitch Wind Turbines" ICARCV 2006.

[6] Kathryn E. Johnson, "Adaptive Torque Control of Variable Speed Wind Turbines", Technical Report, National Renewable Energy Laboratory (US), 2004.

Fig. 9, Response of both the electric power and speed turbine to wind speed changes
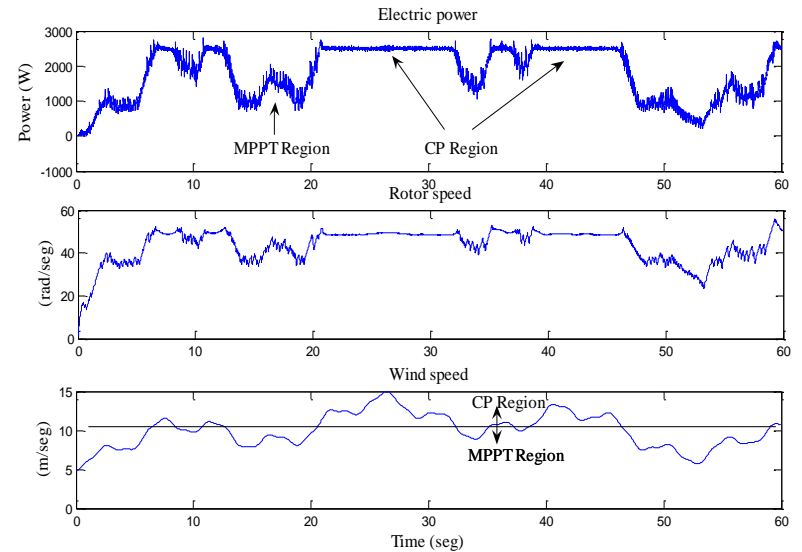

Fig.10, Response of both the electric power and speed turbine to wind speed changes

\section{6.- Conclusion}

A control system for small wind turbines has been presented in this paper. The proposed control system has a variable structure depending on the operation region. In the MPPT region, a speed turbine control loop is used to follow the maximum available power point. In the nominal power region, a linear control is used to maintain the power close to a reference value in spite of high wind speeds. For this CP region, it has been shown that closing the power control loop by cascade compensation of the inner speed loop is preferred to use an inner torque control loop.

\section{REFERENCES}

[1] L. Harnefors, "Speed estimation from noisy resolver signal" in Proc. 6th Int. Conf. Power Electron. And Variable Speed Drives, 1996, Page(s). 279-282.

[2] Ming Y., Gengyin L., Ming Z., Chengyong Z., "Modeling of the Wind Turbine with a Permanent Magnet Synchronous Generator for Integration", IEEE Power Engineering Society General Meeting, Jun. 2007.

[3] F.D. Bianchi, H. De Battista, R.J. Mantz, "Wind Turbine Control Systems", Principles, Modelling and Gain Scheduling Design, Springer-Verlag, 2007. 